\title{
Berry Pectins: Microwave-Assisted Extraction and Rheological Properties
}

\author{
Katalin Bélafi-Bakó • Petra Cserjési • Sándor Beszédes • \\ Zsófia Csanádi • Cecília Hodúr
}

Received: 11 June 2010 /Accepted: 27 April 2011 /Published online: 11 May 2011

(C) Springer Science+Business Media, LLC 2011

\begin{abstract}
Press residues formed during processing of berry fruits are regarded as valuable pectin sources. In this work, pectins were extracted from press residues obtained by processing of various fresh berry fruits: red and black currant, raspberry and elderberry. The extraction was carried out by conventional and microwave-assisted methods. Comparing the two methods, the microwave-assisted process gave significantly better results. The rheological behaviour of the pectins extracted was studied, and we found that the gels of pectins from berry press residues are somewhat weaker than gel of commercial citrus pectin, but stronger than that of commercially available apple pectin. Red currant pectin was found to possess outstanding values regarding gel-forming capacity and thickening effect.
\end{abstract}

Keywords Red and black currant · Raspberry · Elderberry · Microwave-assisted extraction

\section{Introduction}

Berry fruits (genus Ribes, Rubus etc.) are rich sources of biologically active compounds; their high vitamin and antioxidant content is well known today (Fukumoto and

K. Bélafi-Bakó $(\bowtie) \cdot$ P. Cserjési $\cdot$ Z. Csanádi

Research Institute on Bioengineering,

Membrane Technology and Energetics, University of Pannonia,

Egyetem u. 10.,

8200 Veszprém, Hungary

e-mail: bako@almos.uni-pannon.hu

S. Beszédes $\cdot$ C. Hodúr

Institute of Mechanical and Process Engineering,

University of Szeged,

Moszkvai krt. 5-7.,

6725 Szeged, Hungary
Mazza 2000). Thus, high amount of berry fruits is being processed nowadays (Koroknai et al. 2008; Sousa et al. 2007). The annual berry production (including raspberry, elderberry, strawberry, red currant and black currant) is approximately $27,000 \mathrm{t}$ in Hungary, though it is difficult to estimate since its majority is grown in small and medium enterprises (SMEs) and small farms. The processing of the fruits results in larger and higher amount of co-products and wastes which can be utilised. In fruit juice production from berries, press residues (cakes) are formed in large quantities, which contain several valuable nutrients, ingredients and compounds (Landbo and Meyer 2001; Hilz et al. 2005). These residues are suitable for pectin recovery, though their pectin content is somewhat lower than other typically pectinrich fruits. For industrial purposes, nowadays, pectin is produced from apple and citrus (Diaz et al. 2009); however, novel sources have been searching for manufacture of other pectins and expected beneficial properties.

Pectin is widely used as thickening, gelling and emulsifying additive in food, cosmetic and pharmaceutical industries (Walter 1991). In the commercial pectin extraction process (http://www.encyclopedia.com/topic/pectin.aspx), acidic solution and high temperature are used; moreover, it is a very time-consuming — up to $12 \mathrm{~h}$-process, having large liquid phase demand. These reasons had led to improve rapid extraction processes, such as the microwave-assisted extraction (MAE; Fishman et al. 2006). Microwave (MW) technique has become a popular heat-generating process in the laboratory scale analytical methods as well as in industrial technologies (Metaxas and Meredith 1993). MW irradiation penetrates into total mass of sludge and causes rapidly a vibration of water molecules at high frequency, and this vibration creates frictional heat and sludge heated volumetrically. Although the quantum energy of microwave radiation is too low to break the primary chemical bonds, but 
some structures can be altered by the energies carried by microwaves, for instance, microwave radiation can cause polarization in tertiary and quaternary structure of macromolecules, it results to breakage of hydrogen bond (Hoz et al. 2005). In MAE processes, microwave energy is used to heat solvents in contact with samples to accelerate the extraction of valuable compounds from the sample matrix into the solvent. Due to the polar character of water molecule, the irradiated microwave energy can be absorbed efficiently; therefore, water is considered as an environmental-friendly solvent for MAE processes (Morales-Muñoz et al. 2006). In the last decades, MAE of organic pollutants, pesticides, phenols, polymers and other bio-compounds became one of the most popular extraction processes, and it has become of interest as an alternative for the conventional methods on account of reduced solvent and process time demand (Eskilsson and Bjorklund 2000; Xiao et al. 2008). Due to the thermal stress effects of microwave irradiation, it can be manifested in the rapid degradation of cell walls (Wang et al. 2007); therefore, the cells appear more opened than in conventional boil water method, and the pectin content of the cell wall is much more extractable (Zhongdong et al. 2006). Kratchanova et al. (2004) reported that MAE has a considerable advantage over the conventional solvent extraction; the yield of pectin can be increased up to $108 \%$ to $240 \%$ as compared to the control, but prolonging the irradiation time led to a decrease in gel strength (Kratchanova et al. 2004).

In this work, our aims were to recover pectins from press residues from various berries (red and black currant, raspberry and elderberry) by using MAE and to test some of the important properties (rheological behaviour and gel forming capacity) of the pectins obtained.

\section{Materials and Methods}

\section{Reagents and Raw Materials}

Purified pectins from apple (Classic AF 202) and citrus were obtained from Herbstreith \& Fox (Germany) and Polding Ltd. (Budapest, Hungary), respectively. All the other chemicals, $i$ propanol, saccharose, citric acid and sodium citrate (analytical grade), were purchased from Fluka (Germany).

Press residues from red currant (Ribes rubrum, cv. Jonker), black currant (Ribes nigrum, cv. Titania), raspberry (Rubus idaeus, cv. Autumn Bliss) and elderberry (Sambucus nigra, cv. Haschberg; from Fitomark '94 Ltd, Tolcsva, Hungary) were obtained after pressing the juice from the fresh fruits by using a Pera PN BUCHER compressor. Press cake was stored deep-frozen $\left(\right.$ at $\left.-18^{\circ} \mathrm{C}\right)$ in polyethylene bags prior to use. The average total solid content of the press cake (on a wet basis) was $23.5 \% \mathrm{w} / \mathrm{w}$.
Extraction Techniques

MAEs were conducted to recover pectins from berry press residues (red and black currant, raspberry and elderberry), which were precipitated by $i$-propanol, then dried under vacuum. Then, the gel-forming properties of the pectin powders obtained were investigated in a standard solution ( $5 \mathrm{~g}$ pectin and $60 \mathrm{~g}$ saccharose in $150 \mathrm{~g}$ distilled water); $\mathrm{pH}$ was adjusted to 3.5. For comparison purposes, the measurements were carried out with apple and citrus pectins as well.

The conventional extraction of pectins from the same berry press residues (red and black currant, raspberry and elderberry) was carried out in a UOP4-type continuous pilot solid/liquid extraction unit from Armfield Ltd. (Hampshire, UK). The proper conditions for the effective extraction were selected by preliminary experiments. The solvent was circulated by a piston pump operated at a flow rate of $0.3 \mathrm{Lmin}^{-1}$. The temperature was adjusted to $80^{\circ} \mathrm{C}$ by using PID controller. Eight hours extraction time was applied. Water was used as a solvent. The press-cake had an average $\mathrm{pH}$ of 6.2, which was suitable for the extraction; thus, $\mathrm{pH}$ was not adjusted. The quantity of sample was $100 \mathrm{~g}$, and the sample to solvent $(\mathrm{S} / \mathrm{S})$ ratio was 1:40.

For MAE, a specially designed and developed microwave cavity resonator (Samsung) was used to achieve homogenous dielectric field using monomode waveform. The magnetron power can be continuously varied between 50 and $700 \mathrm{~W}$ at an operating frequency of $2.45 \mathrm{GHz}$. During irradiation, the samples were closed into a polytetrafluor-ethylene (PTFE) vessel to avoid evaporation. Based on our previous investigations (Hodúr et al. 2007) regarding the pectin yield, the optimum parameters using water as solvent were as follows: $15 \mathrm{~W} / \mathrm{g}$ specific microwave power level (the ratio of magnetron power to the mass of press-cake in terms of dry weight basis), solid to solvent ratio of $1: 10$ and extraction time of $30 \mathrm{~min}$. For the precipitation of pectin, isopropyl alcohol was used with a concentration of $50 \%$ in solution. The precipitation was repeated three times, and after precipitation, the coagulated pectin was separated by filtering through a cloth filter. The coagulated pectin was dried in a vacuum drying cabinet (with 0.95 bar vacuum, at $45^{\circ} \mathrm{C}$ ) to achieve a final moisture content of $9.6 \%$ on dry basis, and afterwards, it was ground and sieved (mesh no. 30). The pectin powder was stored in polyethylene bags in the refrigerator at $5^{\circ} \mathrm{C}$.

\section{Gelling and Rheological Experiments}

In the gelling experiments, $40 \%$ saccharose and $5 \%$ pectin powder by weight of the total final mixture were suspended in hot water to compare the gelling effect of the various pectin samples (Pagán and Ibarz 1999). The pH was 
adjusted to 3.5 , and suspension was cooled in a thermostat at $5^{\circ} \mathrm{C}$ (Iglesias and Lozano 2004).

To study rheological properties, behaviour of the gels obtained/prepared from the pectin extracted conventionally and microwave-assisted from various pectin sources was investigated. The flow properties of pectin gels were characterized by flow curves which were determined by Rheotest 2.1 thermostated rheoviscometer (Rheotest Messgerate Gmbh, Germany) with coaxial cylinders and cone-and-plane gap with a cone diameter of $36 \mathrm{~mm}$ and angle of $5^{\circ}$. The shear rate varied between 11.3 and $460 \mathrm{~s}^{-1}$. The connection between the shear speed and the shear stress characterizes the rheological and substantial properties of gels. For measuring the temperature dependence of the flow properties of the samples, a vibro viscometer (A\&D, Japan) was used. To determine the effect of temperature on viscosity, the values were fitted to an Arrhenius-type equation (Rao et al. 1984).

\section{Statistical Analysis}

All the methods used were investigated from the statistical analysis point of view. In case of viscosity measurements, we have carried out experiments at least in triplicate, and the average values were given in the figures if the standard error was less than $5 \mathrm{mPa}$-s. Otherwise, the experiments were repeated. Determining the flow properties, the accuracy was found to be $0.2 \%$ in the measurement range of our experiments (between 0 and $700 \mathrm{~Pa}$ ), and it was independent of the quality of pectin gel obtained from various sources. (Thus, error bars were not presented in the figures in order to avoid showing too complicated diagrams.)

\section{Results}

\section{Extraction}

A comparative series of experiments (altogether 22 measurements, at least three replicates for each sample) was carried out to determine the yield of pectin extraction from press residues in cases of various berries: red and black currant, raspberry and elderberry by using conventional extraction technique and MAE. In our experiments earlier (Kiss 2009), it turned out that the $\mathrm{pH}$ is in the advantageous acidic range (between 3.2 and 4.5) in all the cases; thus, no $\mathrm{pH}$ adjustment was applied. The extraction data are summarized in Table 1 . It can be seen that higher yields were achieved by using MAE in every fruit than by conventional extraction.

\section{Rheological Properties of the Pectins}

Pectins obtained from black currant by the two techniques were tested comparatively. Gel formation ability, viscosity and rheological properties were investigated. In Fig. 1, the viscosity data of the gels from black currant pectins are presented as a function of temperature. As it can be seen from the viscosity data, the pectin obtained by microwave extraction (MW pectin) forms higher viscosity gel at lower temperature; thus, it has higher thickening effect than the other one at lower temperature, which can be characterised as a more beneficial character.

Rheological behaviour of gels can be described by the power law relationship (Rao et al. 1984):

$\sigma=K(D)^{n}$

where $\sigma$ is the shear stress (Pascal), $D$ is the shear rate (1 per second), $K$ is the consistency index (Newton-second per square meter) and $n$ is the flow behaviour index (dimensionless). Flow behaviour index reflects the viscosity of the solution, i.e. $n=1$ if the solution behaves Newtonian and $n \neq$ 1 if the solution behaves non-Newtonian (Lapasin and Pricl 1999). Flow curves of the gels extracted conventionally and microwave-assisted from black currant pectins were determined (Fig. 2).

In Fig. 2, it can be seen that the flow curve of the gel from the pectin obtained by conventional extraction has a flow index of 0.9388 , not far from 1 ; thus, it is a Newtonian behaviour, having lower thickening effect. On the contrary, the flow curve obtained from MAE gel has a 0.7438 flow index. The lower flow index shows a typical pseudoplastic

Table 1 Data on pectin extraction from press residues

\begin{tabular}{|c|c|c|c|}
\hline \multirow[t]{2}{*}{ Substance } & \multicolumn{2}{|c|}{$\begin{array}{l}\text { Pectin yield of extraction [\%] (refer to total water-soluble } \\
\text { pectin content) }\end{array}$} & \multirow[t]{2}{*}{ Original total pectin content [\%] (Kiss 2009 ; refer to dry weight) } \\
\hline & Microwave extraction & Hot water extraction & \\
\hline Red currant & $68.3 \pm 0.22$ & $50.1 \pm 0.34$ & 0.9 \\
\hline Black currant & $64.1 \pm 0.34$ & $41.4 \pm 0.13$ & 1.1 \\
\hline Raspberry & $83.7 \pm 0.19$ & $73.8 \pm 0.07$ & 0.6 \\
\hline Elderberry & $59.4 \pm 0.51$ & $41.3 \pm 0.24$ & 1.3 \\
\hline
\end{tabular}




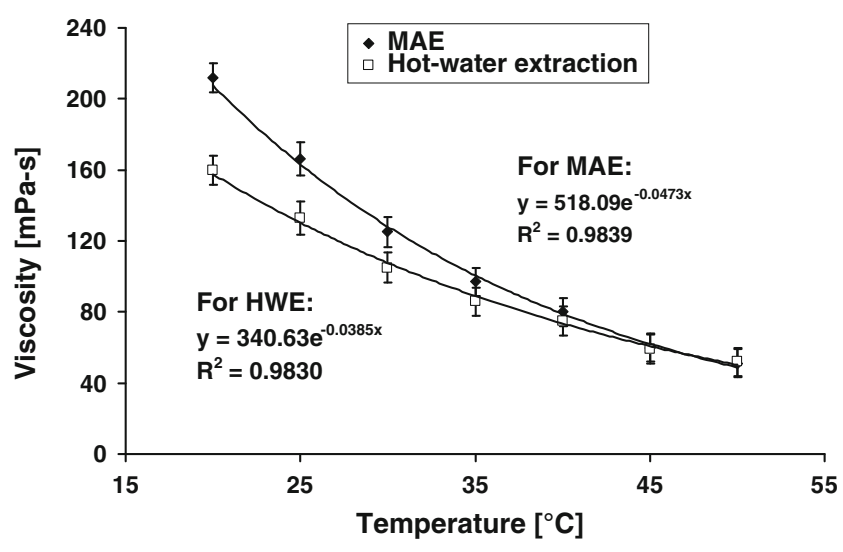

Fig. 1 Viscosity of pectin gels obtained from black currant by conventional hot water and microwave-assisted extractions

behaviour when the values of the flow index are lower than 1. The explanation for this finding may be the special effect of the microwave power on the pectin structure during the extraction procedure. The microwave used to irradiate the samples probably caused a deeper rupture in the cell wall, consequently a more efficient extraction, resulting in a more compact pectin structure than the extraction alone. Based on these results, further extractions to recover pectins from various berries were carried out by microwave technique.

The viscosity data of the pectin gels obtained from the berry press residues and apple and citrus as a function of temperature were determined and presented in Fig. 3. Viscosity behaviour of the berry pectin gels is quite similar to the commercially available pectin gels; the data are located between the viscosity level of apple and citrus pectin gels. At higher temperatures, the viscosity difference between the various pectin solutions is decreasing. Viscosity of red currant pectin solution is practically the same as the value of citrus pectin in the range of $20-50^{\circ} \mathrm{C}$ temperature, taking into account the accuracy of the

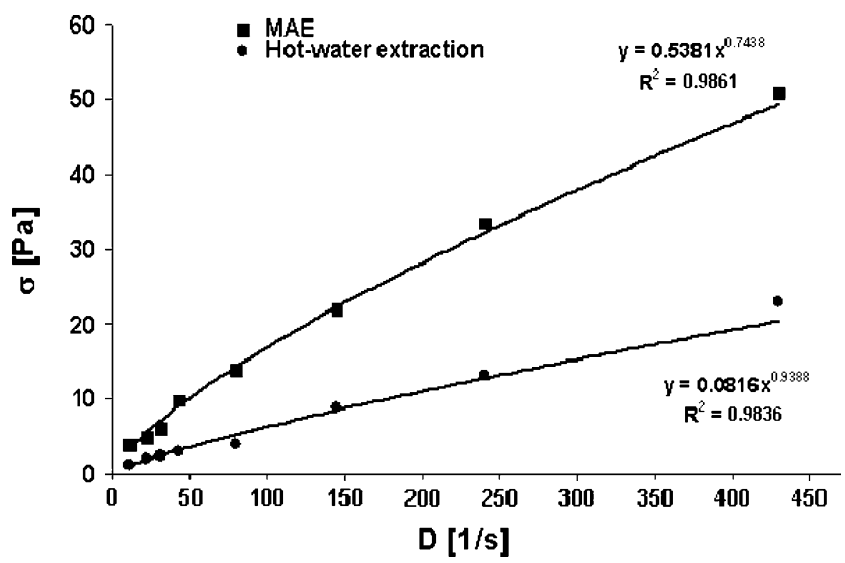

Fig. 2 Flow curves: shear stress $(\sigma)$ vs. shear rate $(D)$ of the pectin gels obtained from black currant by conventional hot water and microwave-assisted extractions

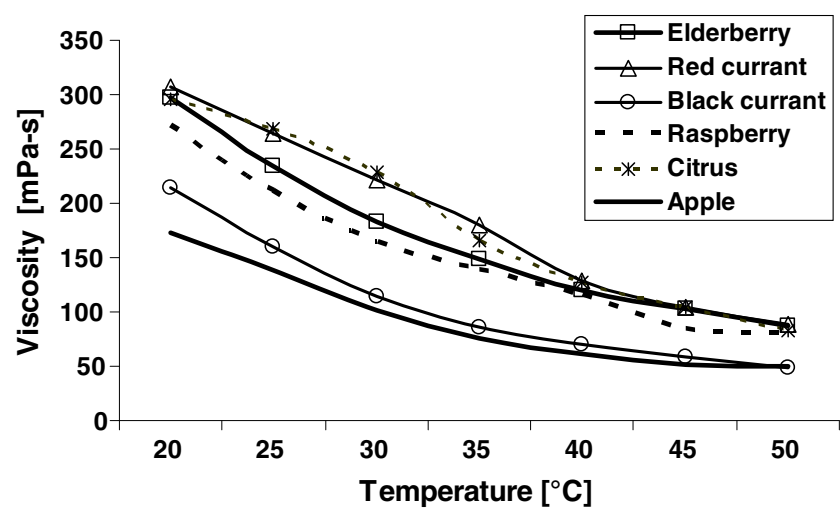

Fig. 3 Viscosity of various pectin gels as a function of temperature

measurement. Moreover, at higher temperatures (above $40^{\circ} \mathrm{C}$ ), viscosity of elderberry pectin is similar to these values. The pectin from black currant shows similar behaviour as apple pectin. As a summary, it was found that viscosities of the various pectins obtained by extraction are quite similar to those commercially available.

An Arrhenius-type equation was fitted to the viscosity values as a function of temperature (Rao et al. 1984; Lapasin and Pricl 1999):

$\eta=\eta_{\infty} \exp \left(E_{\mathrm{a}} / R T\right)$

where

$\eta \quad$ Viscosity (millipascal-second)

$\eta_{\infty}$ Pre-exponential factor (millipascal-second)

$R \quad$ Perfect gas constant $(8.314 \mathrm{~J} / \mathrm{mol} \mathrm{K})$

$E_{\mathrm{a}}$ Activation energy for flow (joule per mole)

$T$ Temperature (Kelvin)

The values of activation energy can be easily determined by a linearization method, as follows:

$\ln \eta=\ln \eta_{\infty}+E_{\mathrm{a}} / R T$

where $E_{\mathrm{a}}$ is given from the slope of the curves. The data calculated are summarised in Table 2. It can be seen that the $E_{\text {a }}$ values are quite similar; the highest value was obtained for black currant pectin. These values are similar to the ones obtained for peach pectin solutions (Pagán and Ibarz 1999).

Flow curves of the pectin gels from various sources were determined by the Rheotest 2 equipment (Fig. 4). As it can be seen from the figure, the rheological features of the pectin gels from various sources-unlike viscosity behaviours - show significant differences. The pectin gels from black currant, elderberry and raspberry are similar to apple pectin and rather different from the flow features of the citrus and red currant pectins. We found that-among the pectins extracted from the berry residues - pectin gel from red currant has the highest thickening effect. 
Table 2 Activation energy values for pectin viscosity data and parameters of the flow curves determined

\begin{tabular}{lccc}
\hline Pectin gels & $E_{\mathrm{a}}[\mathrm{kJ} / \mathrm{mol}]$ & Consistency $(K)$ & Flow behaviour $(n)$ \\
\hline Black currant (microwave extraction) & 39.1 & 0.55 & 0.737 \\
Black currant (hot water extraction) & 32.2 & 0.082 & 0.939 \\
Apple & 33.3 & 0.626 & 0.699 \\
Elderberry & 32.6 & 0.533 & 0.811 \\
Raspberry & 33.1 & 1.284 & 0.653 \\
Citrus & 35.4 & 41.158 & 0.556 \\
Red currant & 34.4 & 14.752 & 0.556 \\
\hline
\end{tabular}

Flow curves of pectin gels from black currant, elderberry and raspberry compared to commercial apple are presented separately in Fig. 5. They are all quite similar, the curves of raspberry and elderberry; moreover, black currant and apple show the same trend, respectively - taking into account the $5 \%$ error level of the measurements.

As a conclusion, we found in the measurement-based on the mechanical modification of gel structure formed as a result of pectins' textural modifying effect- that the pectins obtained from the berry residues by MAE have similar behaviour as that of commercial apple pectin, or even their features are better (although they do not exceed the features of citrus pectin gel).

The parameters of the flow curves determined for the pectin gels from various sources are summarised also in Table 2, where $K$ (consistency index) and $n$ (flow behaviour index) are listed. From the data, it is clear that pectin structure from red currant approaches closely to the features of citrus pectin since it has the highest consistency parameter among the berry fruits.

The pectin gels from the other berries show pseudoplastic features, and these pectins form stronger gels than commercial apple pectin, which is proven by their higher consistency and low index. The only exception is pectin gel from black currant by non-MW extraction, which is

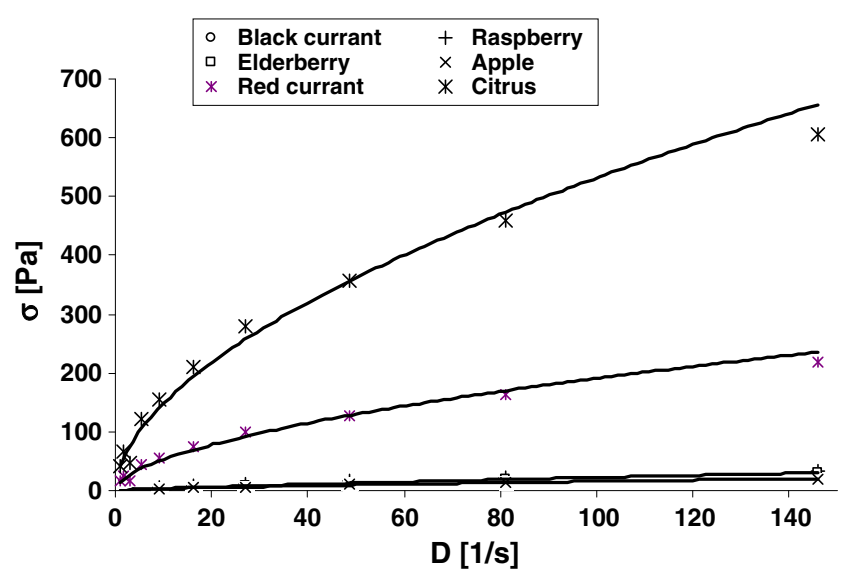

Fig. 4 Flow curves: shear stress $(\sigma)$ vs. shear rate $(D)$ of pectin gels obtained from various sources rather a Newtonian medium having a flow index close to 1 and a very low consistency index; thus, its gel-forming power and thickening effect are much lower than the other berries. However, it can be applied for other purposes, like manufacture of galacturonic acid by enzymatic hydrolysis of the pectin obtained (Bélafi-Bakó et al. 2007).

\section{Conclusions}

As a summary of the first part of our experimental results, we concluded that it is worth to use microwave technique during the extraction of pectin since it results to higher yield and better pectins from the rheological point of view, which seems very important from engineering aspects.

In the second part of the experiments, we found that the rheological features of the pectin gels obtained from berries by microwave-assisted/intensified extraction are weaker than that of commercial citrus pectin, but also better than the commercially available apple pectin. Red currant pectin has outstanding values regarding consistency and flow index; thus, its gel-forming capacity is comparable with citrus pectin.

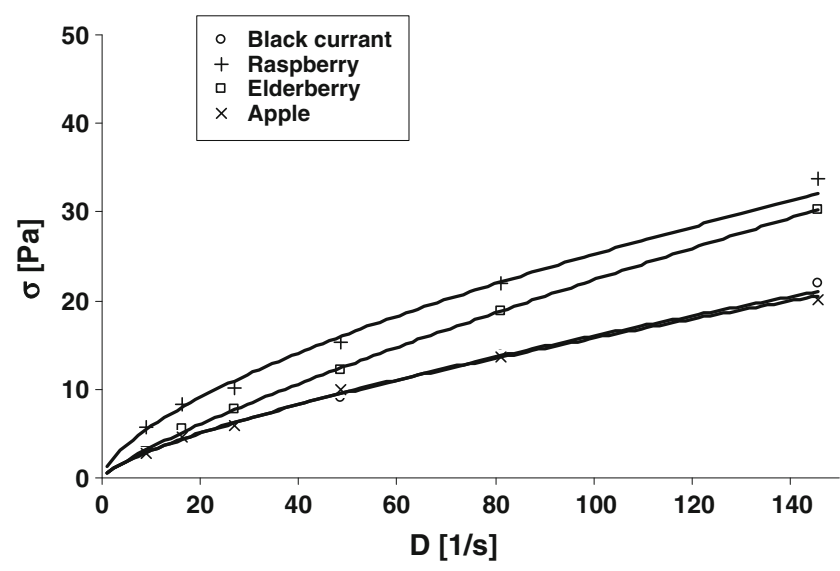

Fig. 5 Flow curves: shear stress $(\sigma)$ vs. shear rate $(D)$ of pectin gels obtained from raspberry, elderberry, black currant and apple 


\section{References}

Bélafi-Bakó, K., Eszterle, M., Kiss, K., Nemestóthy, N., \& Gubicza, L. (2007). Hydrolysis of pectin by Aspergillus niger polygalacturonase in a membrane bioreactor. Journal of Food Engineering, $78,438-442$.

Diaz, E. L., Giannuzzi, L., \& Giper, S. A. (2009). Apple pectic gel produced by dehydration. Food and Bioprocess Technology, 2(2), 194-207.

Eskilsson, C. S., \& Bjorklund, E. (2000). Analytical-scale microwave assisted extraction. Journal of Chromatography, 840, 59-70.

Fishman, M. L., Chau, H. K., Hoagland, P. D., \& Hotchkiss, A. T. (2006). Microwave assisted extraction of lime pectin. Food Hydrocolloids, 20, 1170-1177.

Fukumoto, L. R., \& Mazza, G. (2000). Assessing antioxidant and prooxidant activities of phenolic compounds. Journal of Agricultural and Food Chemistry, 48, 3597-3604.

Hilz, H., Bakx, E., Schols, H., \& Voragen, A. (2005). Cell wall polysaccharides in black currants and bilberries - characterisation in berries, juice, and press cake. Carbohydrate Polymers, 59, 477-488.

Hodúr, C., Beszédes, S., László, Z., \& Szabó, G. (2007). Extraction and biodegradability of marcs. In: Proceedings of 3rd CIGRFood and Agricultural Products, Processing and Innovations Naples, Italy, 24-26 September 2007 (CD-ROM).

Hoz, A., Diaz-Ortiz, Á., Moreno, A. (2005). Microwaves in organic synthesis. Thermal and non-thermal microwave effects. Chemical Society Reviews, 34, 164-178. http://www.encyclopedia.com/topic/ pectin.aspx

Iglesias, M. T., \& Lozano, J. E. (2004). Extraction and characterization of sunflower pectin. Journal of Food Engineering, 62, 215223.

Kiss, K. (2009). Extraction and enzymatic hydrolysis of pectins. Ph.D. dissertation. Veszprem, Hungary: University of Pannonia.

Koroknai, B., Csanádi, Z., Gubicza, L., \& Bélafi-Bakó, K. (2008). Preservation of antioxidant capacity and flux enhancement in concentration of red fruit juices by membrane processes. Desalination, 228, 295-301.
Kratchanova, M., Pavlova, K. W., \& Panchev, I. (2004). The effect of microwave heating of fresh orange peels on fruit tissue and quality of extracted pectin. Carbohydrate Polymers, 56(2), 181185.

Landbo, A. K., \& Meyer, A. S. (2001). Enzyme-assisted extraction of antioxidative phenols from black currant juice press residues (Ribes nigrum). Journal of Agricultural and Food Chemistry, 49, 3169-3177.

Lapasin, R., \& Pricl, S. (1999). Rheology of industrial polysaccharides. New York: Chapman \& Hall.

Metaxas, A. C., \& Meredith, E. M. (1993). Industrial microwave heating (Power engineering series, Vol. 4, pp. 63-65). UK: Peter Peregrinus Ltd.

Morales-Muñoz, S., Luque-García, J. L., \& de Castro, L. (2006). Pure and modified water assisted by auxiliary energies: an environmental friendly extractant for sample preparation. Analytica Chimica Acta, 557, 278-286.

Pagán, J., \& Ibarz, A. (1999). Extraction and rheological properties of pectin from fresh peach pomace. Journal of Food Engineering, 39, 193-201.

Rao, M. A., Cooley, H. J., \& Vizali, A. A. (1984). Flow properties of concentrated juices at low temperature. Food Technology, 38, $116-119$.

Sousa, M. B., Canet, W., Alvarez, M. D., \& Fernandez, C. (2007). Effect of processing on the texture and sensory attributes of raspberry (cv. Heritage) and blackberry (cv. Thornfree). Journal of Food Engineering, 78, 9-21.

Walter, R. H. (1991). The chemistry and technology of pectin (p. 17). New York: Academic.

Wang, S., Chen, F., Wu, J., Wang, Z., Liao, X., \& Hu, X. (2007). Optimization of pectin extraction assisted by microwave from apple pomace using response surface methodology. Journal of Food Engineering, 78, 693-700.

Xiao, W., Han, L., \& Shi, B. (2008). Microwave-assisted extraction of flavonoids from Radix astragali. Separation and Purification Technology, 62, 614-618.

Zhongdong, L., Guohua, W., Yunchang, G., \& Kennedy, J. F. (2006). Image study of pectin extraction from orange skin assisted by microwave. Carbohydrate Polymers, 64, 548-552. 